\title{
CURRENT TRENDS AND DEVELOPMENTS OF PRODUCT MODULARISATION - A BIBLIOMETRIC ANALYSIS
}

\author{
Mertens, Kai G. (1); \\ Rennpferdt, Christoph (2); \\ Greve, Erik (2); \\ Krause, Dieter (2); \\ Meyer, Matthias (1) \\ 1: Hamburg University of Technology - Institute of Management Accounting and Simulation; \\ 2: Hamburg University of Technology - Institute of Product Development and Mechanical \\ Engineering Design
}

\begin{abstract}
Product modularisation continuously draws attention of scholars and practitioners since it supports organizations and industries to sustain in high product and service variety at reasonable costs and greater flexibility. This paper aims at revealing current trends and developments in the field of product modularisation by identifying the intellectual structure using a bibliometric review. Our sample accrues 1,366 publications from 2016 up to 2020 across disciplines while using bibliometric coupling composes a network. Analysing the network on similarities, we can not only find clusters of servitisation, closed-loop supply chains, and platform collaboration, because we also identify three trends of digital innovation, sustainability, and platform eco-systems. An analysis of authors currently indicates less integrated communities, which do not entirely refer to each other despite the similarity in their research. Collectively, the study suggests a timely update of current scholar activities and discussions in the field of product modularisation.
\end{abstract}

Keywords: Product Modularisation, Digitalisation, Sustainability, Collaborative design, Industry 4.0

\section{Contact:}

Mertens, Kai G.

Hamburg University of Technology

Institute of Management Accounting and Simulation

Germany

kai.mertens@tuhh.de 


\section{INTRODUCTION}

Product modularisation draws attention of practitioners and policymakers since it supports organizations and industries to sustain high product and service variety at reasonable costs and greater flexibility (Bonvoisin et al., 2016, Otto et al., 2016, Sanchez and Mahoney, 1996). The large interest also attracts scholarly attention and leads to a great body of potential research across various disciplines. Under this circumstance, however, it is hard to be informed about the latest knowledge beyond one's own discipline, and researchers face increasing effort costs to grasp a more global view (Börner et al., 2005, Martin, 2012). As a result, scholars may miss tracking ongoing developments across neighboring disciplines and may pay less attention to emerging trends.

This paper aims to reveal the latest trends and developments from the last four years $(2016-2020)$ to provide an update about product modularisation to support knowledge exchanges among scholars and other stakeholders. The study applies a bibliometric analysis that depict research field's intellectual structure through a network of publications, which can be analysed on similarity and discussed topics. Bibliometric analyses have been widely acknowledged as suitable to capture intellectual structures of research fields (Chen and Song, 2019, Hauke et al., 2017). While classical reviews are substantial and provide detailed insight into specific themes, bibliometric reviews complement existent reviews and objectively sample beyond one discipline (Meyer et al., 2011). Thus, using a bibliometric analysis supplies an overview of similar publications and their potential knowledge bases and discussions that can be used to suggest trends and developments.

We are using a sample of 1,366 publications from 2016 up to 2020 across various disciplines to proxy the intellectual structure of the field of product modularisation. Specifically, we use bibliographic coupling to compose a network that allows us to analyse and discuss the similarities by identifying and comparing clusters. The clusters are potentially knowledge bases such as product modularisation fundamentals in engineering design or closed-loop supply chains. Also, we create a bibliographic network of authors to unravel current research communities of authors to point at barriers and fruitful collaborations. Collectively, the study provides a timely update for scholars and practitioners about current trends and developments in the field of product modularisation.

The remainder of the paper is as follows: Section 2 is a short introduction to introduce bibliometric analyses but focuses on the sampling process and its descriptive results. Section 3 figures the field's intellectual structure by a bibliographic coupling and identifies the authors' communities. Section 4 discusses and suggest some implication based our findings.

\section{BIBLIOMETRIC ANALYSIS}

Because bibliometric analyses suggest overviews about scientific activities, there is a need to collect a sample of publications using databases (Garfield et al., 1983). Bibliometric research requires data about publications entailing author names and citations, including their number of citations and cited references (Small and Sweeney, 1985). The systematic data collection process is independent of researchers' backgrounds and easy to reproduce, given the search syntax (Tranfield et al., 2003). Both ensure greater objectivity in the data collection and fosters the validity and reproducibility of subsequent analyses.

Applying bibliometric analyses relies on a unit of analysis (e.g., citations, cited references, authors, journals, or others) and an approach to measure the relationship (e.g., bibliographic coupling, cocitation analysis, or co-occurrence). Each analysis unit captures a particular meaning for interpretation, while the approaches provide information on similarities. In this study, we apply bibliographic coupling employing publications in the given time as the unit of analysis and their cited references as the approach.

The choice of the analysis unit and approaches have continuously matured and offer rich guidance of similar applications and papers (Chen and Song, 2019, Randhawa et al., 2016). We select bibliographic coupling since it is most suitable to get an actual overview of the current research front (Boyack and Klavans, 2010). By contrast, a co-citation analysis accentuates the cited references, thereby outlining the foundations of a research field (Gmür, 2003). Lastly, our bibliographic network conceptualizes a picture of similar publications in which we identify clusters to depict an intelligible structure in the field. 
Figure 1 demonstrates how bibliographic coupling works by exemplifying it by six publications (i.e., A, B, C, D, E, and F). A and B are bibliographically coupled in the strength of two (i.e., strength is the number of couplings) because the reference list of both papers shares two cited references (i.e., $\mathrm{C}$ and $\mathrm{D}$ ). By contrast, $\mathrm{E}$ and $\mathrm{F}$ are only individually cited by $\mathrm{B}$ and $\mathrm{A}$, delimiting no coupling. The computational software VOSviewer (van Eck and Waltman, 2010) allows us to analyse each publication in its bibliographic coupling with all other publications in the sample. As a result, we retrieve a large-scale matrix of couplings, in other words, publications' shared cited references to other publications, which are normalized (see van Eck and Waltman, 2009). Finally, the comparative assessment of the couplings results in a matrix similarity, which is used to identify clusters in the network.

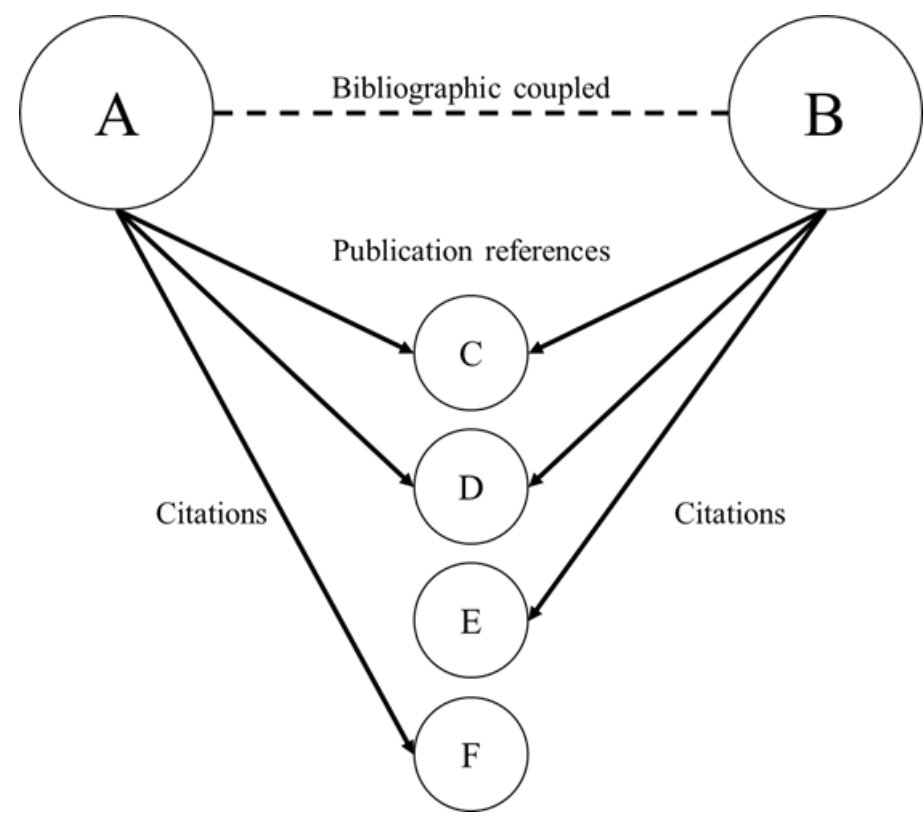

Figure 1. Example of a bibliographic coupling according to Boyack and Klavans (2010)

\subsection{Data collection}

A critical step in each bibliometric analysis pertains to the data collection because the sample is the proxy of the research field. Here, we use the Web of Science database due to its data quality and easy access and proceed as follows. First, we determine the syntax used for our data collection as '(modular* OR commonal* OR "product-platform*") AND (product\$)' integrating the terms of modular, modularity, modularisation, commonality, product platform, and products. Because product modularisation results in modularity, it is necessary to include all dimensions of modularity with respect to commonality and product platforms (Salvador, 2007). The keyword 'product' is essential because it supports a narrower collection, excluding non-physical platforms such as software systems or biological systems. Here, we want to clarify that we understand product modularisation in the context of engineering and management-related disciplines.

Second, we apply the syntax in the time horizon between 2016 and 2020 and obtain 1,366 publications proxying the current intellectual landscape of product modularisation. Our author team checked each publication individually for artifacts to attain higher consistency in the sample. We have not found any duplicates or natural science publications, but some cited references have peculiarities in writing and abbreviations (i.e., Baldwin, C. or Baldwin, C. Y.). Collectively, we strive to capture as many inconsistencies as possible to provide a robust bibliometric sample to revisit current trends and developments in the field of product modularisation.

\subsection{Descriptive analysis of the sample}

Table 1 gives insight into the data collected and depicts the core publications and journals by citations. Table 1 (left) indicates the most cited publications in the sample. There, Nambisan et al. (2017) are by far the most influential publication in the sample. Although they do not explicitly focus on product modularisation, they point out that digital innovation requires more affordances in platform development. Yin et al. (2017) and Oztemel and Gursev (2020) discuss the role of product modularity 
in the context of industry 4.0 and the internet of things (IoT). They review how hardware and software modular interact and become more integrated. Similarly, Cenamor et al. (2017) stress the role of product modularisation and its potentially resulting platform to facilitate servitisation and innovation in regard of digitalisation.

Table 1. Example of a table

\begin{tabular}{lll}
\hline$\#$ & $\begin{array}{l}\text { Most cited publications } \\
\text { \#Citations [Percentage] }\end{array}$ & $\begin{array}{l}\text { Most cited journals } \\
\text { \#Citations [Percentage] }\end{array}$ \\
\hline 1 & Nambisan et al. (2017) & Int. Journal of Production Research \\
& \#184 [3.09\%] & \#376 [6.31\%] \\
2 & Yin et al. (2017) & Int. Journal of Cleaner Production \\
& \#84 [1.41\%] & \#348 [5.84\%] \\
3 & Oztemel and Gursev (2020) & Int. Journal of Production Economics \\
& \#84 [1.41\%] & \#276 [4.63\%] \\
4 & Song and Sakao (2017) & MIS Quarterly \\
& \#80[1.34\%] & \#195 [3.27\%] \\
5 & Cenamor et al. (2017) & Journal of Mechanical Design \\
& \#66[1.11\%] & \#157 [2.63\%] \\
6 & Carlgren et al. (2016) & Journal of Intelligent Manufacturing \\
& \#55 [0.92\%] & \#138 [2.32\%] \\
7 & Davis (2016) & Journal of Engineering Design \\
& \#52 [0.87\%] & \#137 [2.30\%] \\
8 & Colfer and Baldwin (2016) & Int. Journal of Operations \& Production Management \\
& \#48 [0.81\%] & \#133 [2.23\%] \\
9 & Seabrooke and Wigan (2017) & European. Journal of Operational Research \\
& \#47 [0.79\%] & \#131 [2.20\%] \\
10 & Jeihoonian et al. (2016) & Int. Journal of Advanced manufacturing \\
& \#45 [0.75\%] & \#115 [1.93\%] \\
\hline Total & \#5961 [100\%] & \#5961 [100\%] \\
\hline
\end{tabular}

Table 1 (right) illustrates the most cited journals in the sample. While the International Journal of Production Research fits the nature of product modularisation, the Journal of Cleaner Production was surprising. The journal predominantly addresses sustainability and environmental outcomes, and it seems that modularity is decisive in this respect. The International Journal of Product Economics covers interdisciplinary articles pertaining to management, operations management, and engineering design. By contrast, MIS Quarterly has considerably less noticed in the field yet but substantiates the rising importance of information systems and digitalisation. Subsequent journals such as the Journal of Mechanical Design or Journal of Intelligent Manufacturing are expected to be involved and delineate the central core base in product modularisation.

\section{RESULTS}

\subsection{Analysing the intellectual structure}

Figure 2 overviews the intellectual structure of product modularisation and depicts 7 clusters. Each cluster has its own colour and influential publications. We consider each cluster and its related publications thoroughly to aggregate the underlying discourse to a knowledge base. Although few knowledge bases are not new, however, we noticed new trends in their discussion. 


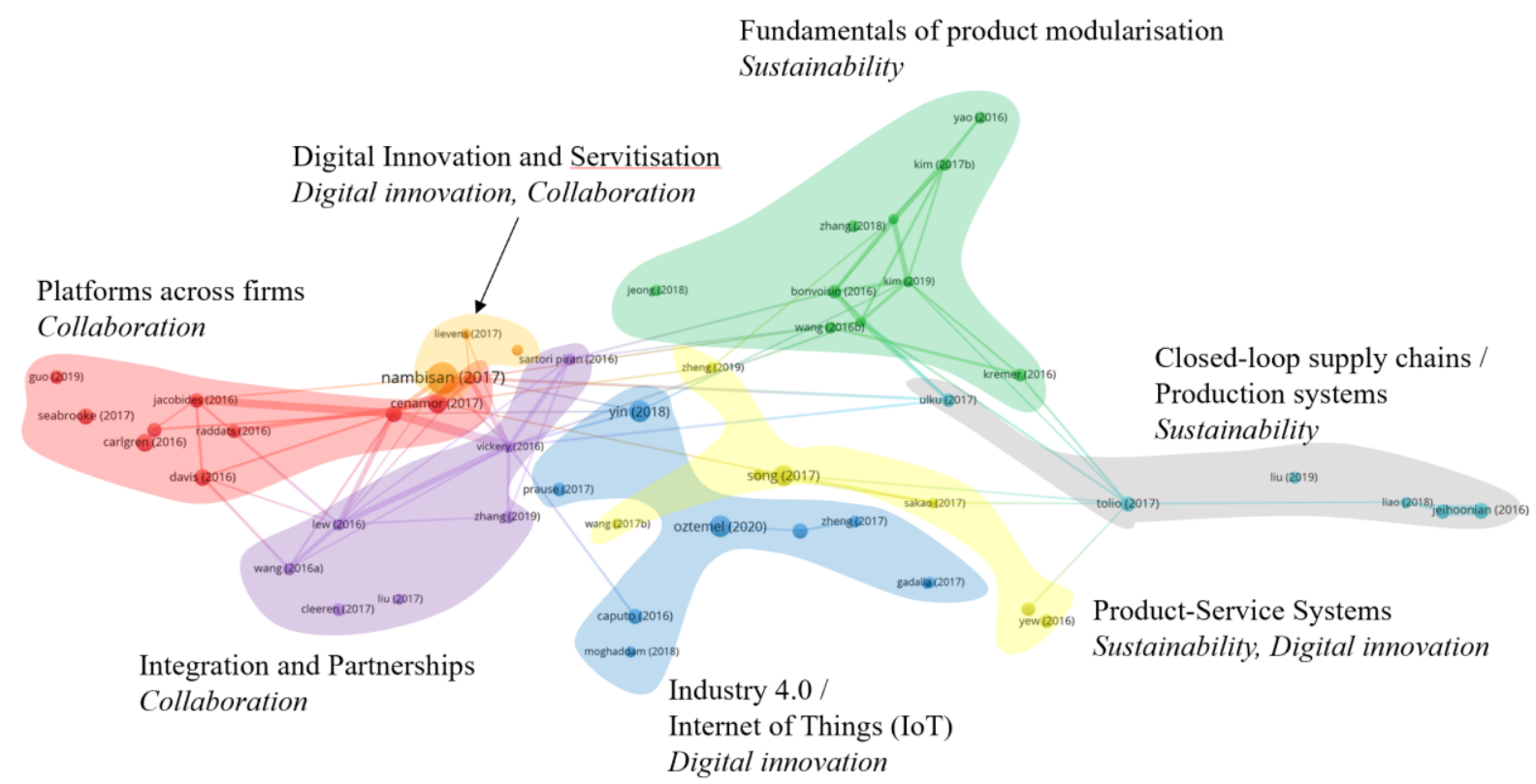

Figure 2. Bibliographic coupling network of publications on product modularisation (20162020). Cluster labels determine the potential emerging knowledge bases. Italic labelling indicates the trend

The green cluster (11 publications) 'Fundamentals of product modularisation' is influenced by fundamental publications adorned with an emphasis on sustainability. While Otto et al. (2016) and Bonviosin et al. (2016) are the latest consolidating publications for understanding and apply product modularisation, nearby publications integrate the goal of sustainability (Jeong et al., 2018, Kremer et al., 2016). Specifically, Kim and Moon (2019) and Kim and Moon (2017) discuss the identification of sustainability in product architectures and product family design. Another discussion concerns the supply chain integration (Wang et al., 2016a) that develops to an individual cluster.

This is the grey cluster ( 6 publications) of 'Closed-loop supply chain' and is dominated by the theme of recursive supply chains, including demanufacturing and pricing of "green products" (Tolio et al., 2017, Ülkü and Hsuan, 2017). To our understanding, this cluster vigorously employs products' life cycles in the context of the supply chain and shows how to 'close' a supply chain by decompositions, redesigns, or durability (Jeihoonian et al., 2016). In sum, the emerging knowledge may connect with the field of circular economy (Geissdoerfer et al., 2017).

The yellow cluster (5 publications) 'Product-Service Systems' is very entangled in the network and is dominated by customisation and how customer information affects and improves product modularisation. Song and Sakao (2017) and Fargnoli et al. (2018) are substantially interwoven and seemingly boundary-spanning. Notably, this cluster considers sustainability as an objective but also pertains to the influence of digital innovation (ElMaraghy and ElMaraghy, 2016).

The blue cluster (9 publications) share a discourse of industry 4.0 and IoT. Most recently, Oztemel and Gursev (2020) summarise state of the art, indicating transformations of robotics and self-decisionmaking system in future manufacturing. Yin et al. (2017) outline potential information flows in industry 4.0 that can leverage new potential of cloud computing using data from product and process designs. For example, Caputo et al. (2016) conceptually comprises IoT and innovation technologies and point at the less connected, more fragmented, research discussions.

The purple cluster ( 7 publications) is influenced by publications that examine modularity in integration and partnerships within/across firms. Vickery et al. (2016) and Piran et al. (2016) find how product modularisation diffuses within firms and subliminal demonstrate further integrations. By contrast, Liu et al. (2017) express the advantages of construction building under increasing modularity, while Wang et al. (2016b) stress the positive implication of modularity in product co-development regarding communication. Both contribute that product modularisation improves joint working and development across organization. 
The red cluster (10 publications) is dominated by discussing how platforms can be used as an enabler for efficient collaboration between partners. Specifically, Cenamor et al. (2017) address the usage of internal or industry-platforms to exploit more services, where Jacobides et al. (2016) discuss the impact of original equipment manufacturer (OEM) on modularity in the automotive sector. It also includes the cross-sectional product development process of design thinking by Carlgren et al. (2016). Within the cluster, there is also the long-enduring discussion of the "mirroring hypothesis" that pertains to one publication (Colfer and Baldwin, 2016), debating the "who drives whom" and indicating a presence of dualism.

The orange cluster (4 publications) is central in the network and is dominated by digital innovation and servitisation. Here, Nambisan et al. (2017) outlines a future research agenda for digital innovation management and undermines platforms as necessary for digital transformation. Similarly, Sjödin et al. (2018) denote digital transformation as a driver for innovation and prescribe how smart factories could use equipment of people, processes, and technology in the future. This cluster forms a foundation for digitalisation and also shows a new branch of innovation.

\subsection{Bibliographic coupling of publications}

The bibliographical analysis in Figure 3 portrays communities by eliciting neighbouring authors citing each other. The bibliographic coupling analyses authors' cited references to find similarities of reoccurring citations to other authors. In other words, the closer authors are in the network, the higher the number of citations between the authors by publications. While frequent referencing is seen as cohesiveness in topics, methods, and understanding, it can also suggest personal familiarity regarding affiliations or mentorships. Thus, we identify clusters to find extant communities in product modularisation.

Figure 3 contains 35 authors with a threshold of at least six publications in our sample and distributed in six clusters. We list each authors' associated affiliations in the figure and bind them by dotted circle if two or more authors share an affiliation. The red cluster is the largest cluster with ten authors that are also strongly linked with each other. Those authors work on similar topics and share a common foundation in the literature, substantiated by joint publications (see Otto et al., 2016, Simpson et al., 2014) and mentorships (Moon and Simpson, 2014). The green cluster consists of eight authors and three affiliations. Their interconnection denotes similarity in citing and suggests familiarity (e.g., Løkkegaard et al., 2018). By contrast, the authors of the yellow and purple clusters are less central in the field. Specifically, each cluster's interaction is restricted to only one author (e.g., ElMaraghy and Bernard). It shows that both clusters are fewer citing publications with the corresponding authors of other clusters. To our understanding, this behaviour can refer to differences in the topics (e.g., Colledani et al., 2016, Otto et al., 2016). The blue cluster is very diverse with respect to affiliations and less dense compared to other clusters. By contrast, the turquoise is dense and from the same affiliations driven by the mentorship between Jiao and Du. 


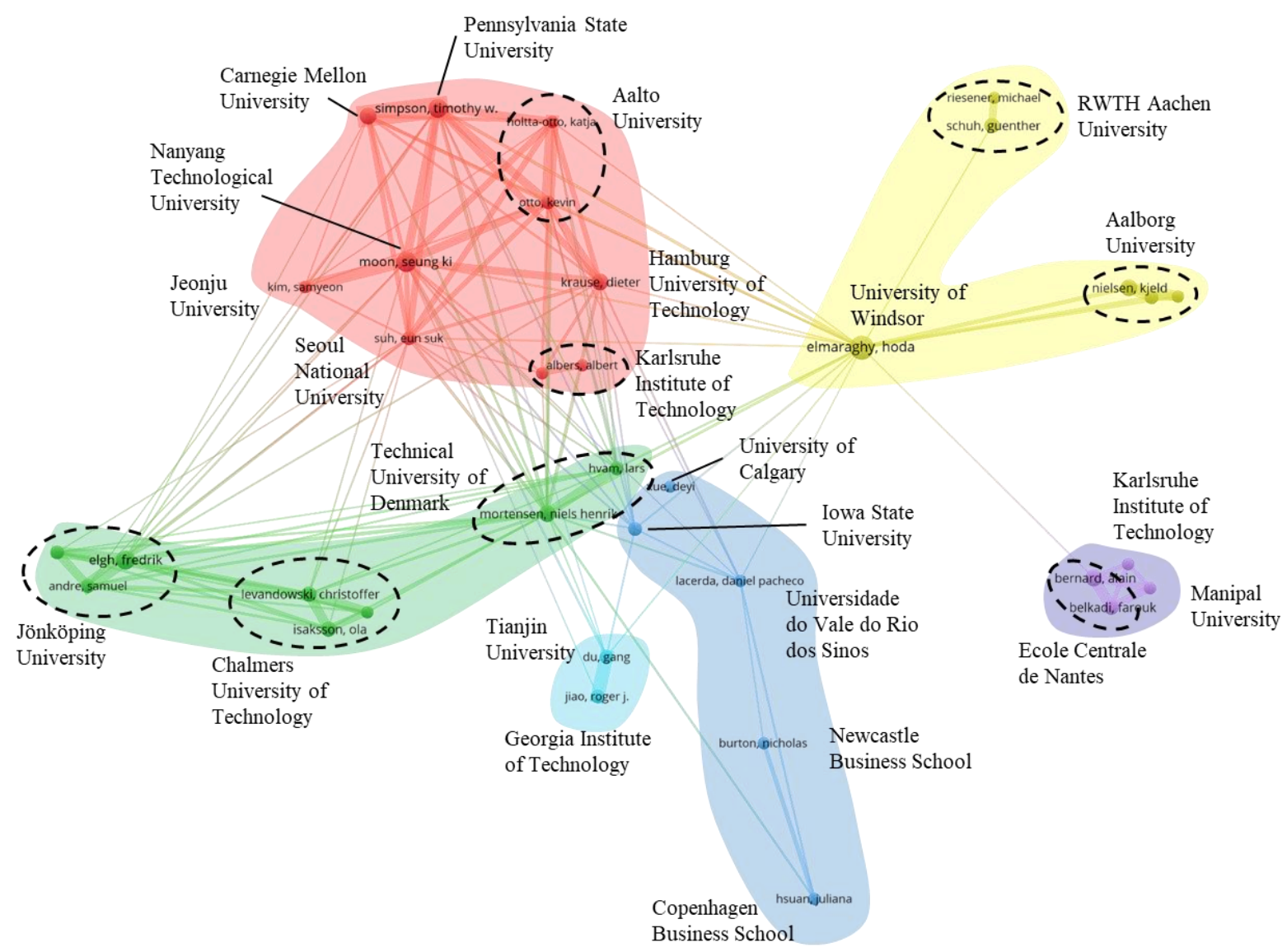

Figure 3. Bibliographic coupling of authors

In sum, the analysis substantiates fragmentation at the level of communities and may raise attention to potential collaborations in two ways. First, it can be fruitful if closer clusters recognise each other to a larger extend in terms of authors and publications. In doing so, the field can receive greater knowledge integration by merging clusters (e.g., red and green or green and blue) and can determine foundations and concepts. Of course, those clusters share a similar background and could even collaborate in common publications. Second, there is a high potential in authors from distant clusters. Literature expects that divergence in backgrounds supports higher novelty in research activities (Raasch et al., 2013, Torraco, 2005, Tranfield et al., 2003) that could build new bridges. Thus, recognising authors' publication beyond one's discipline can start knowledge integration processes or even new discussions despite potentially distinct topics.

\section{DISCUSSION AND CONCLUSION}

The study reviews recent scholarly activities in the field of product modularisation and analysing its intellectual structure by a bibliometric network to suggest current developments and trends. A descriptive analysis documents that a few publications focus on digital innovation and sustainability and accumulate extensive citations. For instance, we find Journal of Cleaner Production and MIS Quarterly among the most cited journals suggesting the neighboring presence of new journals.

The analysis of the network of the bibliographic coupling unravels several clusters that describe the current development. The development consists of emerging knowledge bases such as digital innovation and servitisation (Nambisan et al., 2017), industry 4.0 and internet of things (IoT) (Oztemel and Gursev, 2020, Yin et al., 2017), integration and collaboration (Wang et al., 2016b), and platforms in industries (Davis, 2016, Jacobides et al., 2016), and closed-loop supply chains (Jeihoonian et al., 2016). Interestingly, digital innovation, platforms across organizations, and Internet of Things (IoT) seem to be less integrated into engineering design discussions yet. Nonetheless, we document that sustainability is associated with the fundamentals of product modularisation, suggesting a new but substantial objective of product modularisation. Using the bibliographic coupling of authors, we document extant 
communities and document their distances and closeness. Interestingly, few communities underly a similar affiliation or a former mentorship, whereas others compose diverse clusters.

The study outlines the three trends of digital innovation (Nambisan et al., 2017, Oztemel and Gursev, 2020), sustainability (Sonego et al., 2018, Song and Sakao, 2017), and platform colloboration across organizations (Davis, 2016, Wang et al., 2016b). New projects of scholars or practitioners could profit from the result since it consolidates current product modularisation discussions. The trends suggest stimuli in product modularisation, and we expect that research continues to examine their implications on existent theoretical concepts (e.g., product architecture or products' life cycles). For example, platform collaboration enters discussions on platform eco-systems while sustainability encloses with the circular economy. Identifying author communities apparently points to divergence not only topicdriven and suggests increasing attention to other communities. We find less integrated communities, which do not entirely refer to each other despite their research similarity.

As with other studies, the study pertains to caveats and can profit from further developments. Bibliometric analyses do not substitute in-depth reviews of knowledge bases in disciplines and, therefore, may lack depth in explanation and discussion. Here, further elaborations on the cluster may give insight into more details. Similarly, the sample is restricted to 2016 up to 2020 and only considers a slice of the discussion of product modularisation, aiming at updating researchers instead of providing a full review. The next steps should be to enlarge the time considered and check for other databases. Specifically, Web of Science can bias the results because proceedings of the Design Society are not included. Thus, our extant data collection of journal publications oversees relevant publications in this regard. Finally, the sample solely concentrated on English literature and may oversee strands of nonEnglish literature (e.g., Krause and Gebhardt, 2018) and theses that are not incorporated in the database (e.g., Mertens, 2020, Ripperda, 2019). Nonetheless, we seek to quickly update researchers about the latest trends and developments in the field of product modularisation.

\section{REFERENCES}

Bonvoisin, J., Halstenberg, F., Buchert, T. \& Stark, R. 2016. A systematic literature review on modular product design. Journal of Engineering Design, 27, 488-514. https://doi.org/10.1080/09544828.2016.1166482

Börner, K., Chen, C. \& Boyack, K. W. 2005. Visualizing knowledge domains. Annual Review of Information Science and Technology, 37, 179-255. https://doi.org/10.1002/aris.1440370106

Boyack, K. W. \& Klavans, R. 2010. Co-citation analysis, bibliographic coupling, and direct citation: Which citation approach represents the research front most accurately? Journal of the American Society for Information Science and Technology, 61, 2389-2404. https://doi.org/10.1002/asi.21419

Caputo, A., Marzi, G. \& Pellegrini Massimiliano, M. 2016. The Internet of Things in manufacturing innovation processes: development and application of a conceptual framework. Business Process Management Journal, 22. https://doi.org/10.1108/BPMJ-05-2015-0072

Carlgren, L., Rauth, I. \& Elmquist, M. 2016. Framing Design Thinking: The Concept in Idea and Enactment. Creativity and Innovation Management, 25, 38-57. https://doi.org/10.1111/caim.12153

Cenamor, J., Rönnberg Sjödin, D. \& Parida, V. 2017. Adopting a platform approach in servitization: Leveraging the value of digitalization. International Journal of Production Economics, 192, 54-65. https://doi.org/10.1016/j.ijpe.2016.12.033

Chen, C. \& Song, M. 2019. Visualizing a field of research: A methodology of systematic scientometric reviews. PLoS One, 14, 1-25. https://doi.org/10.1371/journal.pone.0223994

Colfer, L. J. \& Baldwin, C. Y. 2016. The mirroring hypothesis: theory, evidence, and exceptions. Industrial and Corporate Change, 25, 709-738. https://doi.org/10.1093/icc/dtw027

Colledani, M., Silipo, L., Yemane, A., Lanza, G., Bürgin, J., Hochdörffer, J., Georgoulias, K., Mourtzis, D., Bitte, F., Bernard, A. \& Belkadi, F. 2016. Technology-based Product-services for Supporting Frugal Innovation. Procedia CIRP, 47, 126-131. https://doi.org/10.1016/j.procir.2016.03.093

Davis, J. P. 2016. The Group Dynamics of Interorganizational Relationships: Collaborating with Multiple Partners in Innovation Ecosystems. Administrative Science Quarterly, 61, 621-661. https://doi.org/10.1177/0001839216649350

Elmaraghy, H. \& Elmaraghy, W. 2016. Smart Adaptable Assembly Systems. Procedia CIRP, 44, 4-13. https://doi.org/10.1016/j.procir.2016.04.107

Fargnoli, M., Haber, N. \& Sakao, T. 2018. PSS modularisation: a customer-driven integrated approach. International Journal of Production Research, 57, 4061-4077. https://doi.org/10.1080/00207543.2018.1481302

Garfield, E., Malin, M. V. \& Small, H. 1983. Citation data as science indicators. Essays of an Information Scientist. https://doi.org/10.1.1.15.4233 
Geissdoerfer, M., Savaget, P., Bocken, N. M. P. \& Hultink, E. J. 2017. The Circular Economy - A new sustainability paradigm? Journal of Cleaner Production, 143, 757-768. https://doi.org/10.1016/j.jclepro.2016.12.048

Gmür, M. 2003. Co-citation analysis and the search for invisible colleges: A methodological evaluation. Scientometrics, 57, 27-57. 10.1023/a:1023619503005

Hauke, J., Lorscheid, I. \& Meyer, M. 2017. Recent Development of Social Simulation as Reflected in JASSS Between 2008 and 2014: A Citation and Co-Citation Analysis. Journal of Artificial Societies and Social Simulation, 20. https://doi.org/10.18564/jasss.3238

Jacobides, M. G., Macduffie, J. P. \& Tae, C. J. 2016. Agency, structure, and the dominance of OEMs: Change and stability in the automotive sector. Strategic Management Journal, 37, 1942-1967. https://doi.org/10.1002/smj.2426

Jeihoonian, M., Kazemi Zanjani, M. \& Gendreau, M. 2016. Accelerating Benders decomposition for closed-loop supply chain network design: Case of used durable products with different quality levels. European Journal of Operational Research, 251, 830-845. https://doi.org/10.1016/j.ejor.2015.12.052

Jeong, B., Wang, H., Oguz, E. \& Zhou, P. 2018. An effective framework for life cycle and cost assessment for marine vessels aiming to select optimal propulsion systems. Journal of Cleaner Production, 187, 111-130. https://doi.org/10.1016/j.jclepro.2018.03.184

Kim, S. \& Moon, S. K. 2017. Sustainable platform identification for product family design. Journal of Cleaner Production, 143, 567-581. https://doi.org/10.1016/j.jclepro.2016.12.073

Kim, S. \& Moon, S. K. 2019. Eco-modular product architecture identification and assessment for product recovery. Journal of Intelligent Manufacturing, 30, 383-403. https://doi.org/10.1007/s10845-016-1253-7

Krause, D. \& Gebhardt, N. 2018. Methodische Entwicklung modularer Produktfamilien - Hohe Produktvielfalt beherrschbar entwickeln, Germany, Berlin, Springer Verlag.

Kremer, G. E., Haapala, K., Murat, A., Chinnam, R. B., Kim, K.-Y., Monplaisir, L. \& Lei, T. 2016. Directions for instilling economic and environmental sustainability across product supply chains. Journal of Cleaner Production, 112, 2066-2078. https://doi.org/10.1016/j.jclepro.2015.07.076

Liu, G., Li, K., Zhao, D. \& Mao, C. 2017. Business Model Innovation and Its Drivers in the Chinese Construction Industry during the Shift to Modular Prefabrication. Journal of Management in Engineering, 33, 04016051. https://doi.org/10.1061/(ASCE)ME.1943-5479.0000501

Løkkegaard, M., Mortensen, N. H. \& Hvam, L. 2018. Using business critical design rules to frame new architecture introduction in multi-architecture portfolios. International Journal of Production Research, 56, 7313-7329. https://doi.org/10.1080/00207543.2018.1450531

Martin, B. R. 2012. The evolution of science policy and innovation studies. Research Policy, 41, 1219-1239. https://doi.org/10.1016/j.respol.2012.03.012

Mertens, K. G. 2020. Measure and manage your products costs right - Using an extended axiomatic design for measuring and managing the costs of products. Hamburg University of Technology. https://doi.org/10.15480/882.2888

Meyer, M., Zaggl, M. \& Carley, K. M. 2011. Measuring CMOT’s intellectual structure and its development. Computational and Mathematical Organization Theory, 17, 1-34. https://doi.org/10.1007/s10588-010-9076-0

Moon, S. K. \& Simpson, T. W. 2014. Platform Valuation for Product Family Design. In: SIMPSON, T. W., JIAO, J. R., SIDDIQUE, Z. \& HÖLTTA-OTTO, K. (eds.) Advances in Product Family and Product Platform Design - Methods \& Applications. Germany, Heidelberg: Springer https://doi.org/10.1007/978-14614-7937-6_7

Nambisan, S., Lyytinen, K., Majchrzak, A. \& Song, M. 2017. Digital Innovation Management: Reinventing innovation management research in a digital world. Mis Quarterly, 41.

Otto, K., Holtta-Otto, K., Simpson, T. W., Krause, D., Ripperda, S. \& Moon, S. K. 2016. Global Views on Modular Design Research: Linking Alternative Methods to Support Modular Product Family Concept Development. Journal of Mechanical Design, 138, 16. https://doi.org/10.1115/1.4033654

Oztemel, E. \& Gursev, S. 2020. Literature review of Industry 4.0 and related technologies. Journal of Intelligent Manufacturing, 31, 127-182. https://doi.org/10.1007/s10845-018-1433-8

Piran, F. a. S., Lacerda, D. P., Camargo, L. F. R., Viero, C. F., Dresch, A. \& Cauchick-Miguel, P. A. 2016. Product modularization and effects on efficiency: An analysis of a bus manufacturer using data envelopment analysis (DEA). International Journal of Production Economics, 182, 1-13. https://doi.org/10.1016/j.ijpe.2016.08.008

Raasch, C., Lee, V., Spaeth, S. \& Herstatt, C. 2013. The rise and fall of interdisciplinary research: The case of open source innovation. Research Policy, 42, 1138-1151. https://doi.org/10.1016/j.respol.2013.01.010

Randhawa, K., Wilden, R. \& Hohberger, J. 2016. A Bibliometric Review of Open Innovation: Setting a Research Agenda. Journal of Product Innovation Management, 33, 750-772. https://doi.org/10.1111/jpim.12312

Ripperda, S. 2019. Methodische Unterstützung zur kostenbasierten Auswahl modularer Produktstrukturen, Germany, Hamburg, Springer. 
Salvador, F. 2007. Toward a Product System Modularity Construct: Literature Review and Reconceptualization. IEEE Transactions on Engineering Management, 54, 219-240. https://doi.org/10.1109/tem.2007.893996

Sanchez, R. \& Mahoney, J. T. 1996. Modularity, flexibility, and knowledge management in product and organization design. Strategic Management Journal, 17, 63-76. 10.1002/smj.4250171107

Seabrooke, L. \& Wigan, D. 2017. The governance of global wealth chains. Review of International Political Economy, 24, 1-29. https://doi.org/10.1080/09692290.2016.1268189

Simpson, T. W., Jiao, J., Siddique, Z. \& Hölttä-Otto, K. 2014. Advances in Product Family and Product Platform Design, USA, NY, New York, Springer.

Sjödin, D. R., Parida, V., Leksell, M. \& Petrovic, A. 2018. Smart Factory Implementation and Process Innovation. Research-Technology Management, 61, 22-31. https://doi.org/10.1080/08956308.2018.1471277

Small, H. \& Sweeney, E. 1985. Clustering the science citation index ${ }^{\circledR}$ using co-citations. Scientometrics, 7, 391-409.

Sonego, M., Echeveste, M. E. S. \& Galvan Debarba, H. 2018. The role of modularity in sustainable design: A systematic review. Journal of Cleaner Production, 176, 196-209. https://doi.org/10.1016/j.jclepro.2017.12.106

Song, W. \& Sakao, T. 2017. A customization-oriented framework for design of sustainable product/service system. Journal of Cleaner Production, 140, 1672-1685. https://doi.org/10.1016/j.jclepro.2016.09.111

Tolio, T., Bernard, A., Colledani, M., Kara, S., Seliger, G., Duflou, J., Battaia, O. \& Takata, S. 2017. Design, management and control of demanufacturing and remanufacturing systems. CIRP Annals, 66, 585-609. https://doi.org/10.1016/j.cirp.2017.05.001

Torraco, R. J. 2005. Writing Integrative Literature Reviews: Guidelines and Examples. Human Resource Development Review, 4, 356-367. https://doi.org/10.1177/1534484305278283

Tranfield, D., Denyer, D. \& Smart, P. 2003. Towards a Methodology for Developing Evidence-Informed Management Knowledge by Means of Systematic Review. British Journal of Management, 14, 207-222. https://doi.org/10.1111/1467-8551.00375

Ülkü, M. A. \& Hsuan, J. 2017. Towards sustainable consumption and production: Competitive pricing of modular products for green consumers. Journal of Cleaner Production, 142, 4230-4242. https://doi.org/10.1016/j.jclepro.2016.11.050

Van Eck, N. J. V. \& Waltman, L. 2009. How to normalize cooccurrence data? An analysis of some well-known similarity measures. Journal of the American Society for Information Science and Technology, 60, 1635-1651. https://doi.org/10.1002/asi.21075

Van Eck, N. J. V. \& Waltman, L. 2010. Software survey: VOSviewer, a computer program for bibliometric mapping. Scientometrics, 84, 523-538. https://doi.org/10.1007/s11192-009-0146-3

Vickery, S. K., Koufteros, X., Dröge, C. \& Calantone, R. 2016. Product Modularity, Process Modularity, and New Product Introduction Performance: Does Complexity Matter? Production and Operations Management, 25, 751-770. https://doi.org/10.1111/poms.12495

Wang, D., Du, G., Jiao, R. J., Wu, R., Yu, J. \& Yang, D. 2016a. A Stackelberg game theoretic model for optimizing product family architecting with supply chain consideration. International Journal of Production Economics, 172, 1-18. https://doi.org/10.1016/j.ijpe.2015.11.001

Wang, J. J., Li, J. J. \& Chang, J. 2016b. Product co-development in an emerging market: The role of buyersupplier compatibility and institutional environment. Journal of Operations Management, 46, 69-83. https://doi.org/10.1016/j.jom.2016.07.002

Yin, Y., Stecke, K. E. \& Li, D. 2017. The evolution of production systems from Industry 2.0 through Industry 4.0. International Journal of Production Research, 56, 848-861. https://doi.org/10.1080/00207543.2017.1403664 